\title{
Defining Tiger Parenting in Chinese Americans
}

\author{
Su Yeong Kim \\ University of Texas at Austin, Austin, Tex., USA
}

\section{Key Words}

Culture $\cdot$ Development $\cdot$ Parenting $\cdot$ Tiger parenting

\begin{abstract}
"Tiger" parenting, as described by Amy Chua [2011], has instigated scholarly discourse on this phenomenon and its possible effects on families. Our eight-year longitudinal study, published in the Asian American Journal of Psychology [Kim, Wang, OrozcoLapray, Shen, \& Murtuza, 2013b], demonstrates that tiger parenting is not a common parenting profile in a sample of 444 Chinese American families. Tiger parenting also does not relate to superior academic performance in children. In fact, the best developmental outcomes were found among children of supportive parents. We examine the complexities around defining tiger parenting by reviewing classical literature on parenting styles and scholarship on Asian American parenting, along with Amy Chua's own description of her parenting method, to develop, define, and categorize variability in parenting in a sample of Chinese American families. We also provide evidence that supportive parenting is important for the optimal development of Chinese American adolescents.

(c) 2013 S. Karger AG, Basel
\end{abstract}

The publication of Amy Chua's [2011] book Battle Hymn of the Tiger Mother created critics and advocates among the public. Chua claims that her strict and overly controlling method of parenting is the "Chinese way" and that her daughters owe their successes to Chua's "tiger" mothering. Indeed, one of Chua's daughters attends Harvard and was invited to play the piano at Carnegie Hall. In her book, Chua pits this "Chinese" way of parenting against American parenting, stating that the American emphasis on developing and enhancing children's self-esteem is the less effective strategy for raising successful children.

Motivated by the strong reaction in the media and the lively discussion of Amy Chua's [2011] book on various social networking sites, three Asian American devel-

\begin{tabular}{ll}
\hline KARGER & ๑ 2013 S. Karger AG, Basel \\
E-Mail karger@karger.com & $0018-716 X / 13 / 0564-0217 \$ 38.00 / 0$ \\
www.karger.com/hde &
\end{tabular}

Su Yeong Kim

Department of Human Development and Family Sciences University of Texas at Austin, 108 E. Dean Keeton St. Stop A2702, Austin, TX 78712 (USA)

E-Mail sykim@prc.utexas.edu 
opmental scholars organized a special issue for the March 2013 issue of the Asian American Journal of Psychology entitled "Tiger parenting, Asian-heritage families, and child/adolescent well-being." Organized by Linda P. Juang, Desiree Baolian Qin, and Irene J.K. Park [2013], the collection of six empirical papers and two commentaries offer scholarly insight into the debate surrounding the "tiger" method of parenting. My paper [Kim, Wang, Orozco-Laprary, Shen, \& Murtuza, 2013b] was part of this special issue, and it refutes many of the claims made by Amy Chua about tiger parenting. In developing this paper, one of the biggest challenges we faced was defining tiger parenting in Chinese Americans. We looked to the classical literature on parenting styles among European Americans, scholarship on Asian American parenting, and Amy Chua's description of her tiger parenting methods in order to develop, define, and categorize parenting variability in our sample of Chinese American families.

\section{Refuting Amy Chua's Claims about Tiger Parenting}

My eight-year longitudinal study [Kim et al., 2013b] of Chinese American families in Northern California collected multi-informant data from the mother, father, and the child for three key developmental periods at four-year intervals: when the target child was an early adolescent attending middle school, a middle adolescent attending high school, and an emerging adult likely to attend college. The first of Chua's claims that my study refuted was that the majority of Chinese American parents are tiger parents. In fact, most of the parents in our sample were classified as "supportive" parents, followed by either "easygoing" or "tiger" parents, with "harsh" parents making up the smallest percentage of parents in the sample. The second claim that my study refuted was that tiger parenting results in superior academic achievement in children. To our surprise, compared to children of supportive parents, children of tiger parents had lower school-reported GPAs in middle school (3.3 vs. 3.5-3.6) and high school (3.01-3.1 vs. 3.3-3.4), and lower educational attainment as emerging adults. In fact, regardless of informant or developmental period, children of supportive parents showed the best developmental outcomes in multiple domains and across time periods.

\section{Supporting Amy Chua's Claims on Parenting Goals of Chinese Americans}

Scholarly research supports Amy Chua's observations about differences in the parenting goals of Asian American parents compared to European American parents. Chao [1995] found that culture plays a critical role in shaping parenting goals and that Asian American mothers' interdependent and collectivistic values translate to encouraging their children toward high academic achievement to bring honor to the family. In contrast, European American mothers' independent and individualistic values translate to emphasizing a sense of self-esteem in their children and focusing on personal well-being. However, according to Way et al. [2013], Chua's notion of parenting does not necessarily resemble the way contemporary parents in China are raising their children. As a second-generation Chinese American, Chua has a notion of the "Chinese way" of parenting which seems to have been frozen in time. 
Two papers in the special issue on tiger parenting suggest that Amy Chua's perspectives on the parenting goals of Chinese parents have evolved. Cheah, Leung, and Zhou [2013] found that Chinese immigrant mothers recognize that the traditional Chinese way of parenting may be too rigid and punitive to be adaptive in the USA. These immigrant mothers espouse parenting strategies that recognize the importance of bicultural socialization and emphasize the co-existence of Chinese and American ways of parenting. According to Way et al. [2013], Chinese mothers in mainland China now emphasize their children's happiness and emotional well-being along with academic achievement as important parenting goals. She finds that parents recognize that the way they were parented as children is no longer adaptive in raising their own children to become gainfully employed in China's new global market economy [Way et al., 2013]. Together, these two studies are suggesting that contemporary Chinese mothers, in both the USA and China, are embracing a combination of Chinese and Western parenting goals in raising their children.

\section{Classic Parenting Profiles for Examining Variation in Parenting among Chinese Americans}

Baumrind's [1966] and Maccoby and Martin's [1983] classic conceptualization of four parenting styles (authoritarian, authoritative, permissive, negligent) guided our thinking about how to approach defining variations in parenting among Chinese American families. These authors focused on high and low levels of responsiveness (warmth) and demandingness (control) as central features of parenting and relied on these features in defining their four parenting styles. Our "parental warmth" dimension also included hostility, in recognition of the pioneering parenting research of Becker [1964]. In addition, we incorporated Darling and Steinberg's [1993] delineation of various types of parental control, ranging from restrictive to firm to coercive types of control.

In summary, we incorporated dimensions of affective parenting (warm vs. hostile) as well as dimensions of behavioral parenting, which included a range of controlling behaviors (monitoring, punitive discipline, psychological control, democratic parenting, and shaming). Moreover, we added the dimension of reasoning (inductive reasoning) as a measure of effective parent-child communication, as recognized by Maccoby and Martin [1983].

\section{Chinese American Parenting}

When Ruth Chao's seminal publication on the Chinese way of parenting appeared in Child Development in 1994, developmental scholars took notice. Her paper attempted to untangle a perplexing conundrum that had begun to emerge in the scholarly literature: Asian American children were doing well academically, while their parents were being described as authoritarian in their parenting. This finding contrasted the widely noted finding in the developmental literature on European Americans - namely, that it is authoritative parenting, rather than authoritarian, that relates to high academic achievement in children. Chao's [1994] paper has since instigated a number of studies on Asian and Asian American parenting that together 
suggest that parenting among these groups may be a combination of both authoritarian and authoritative parenting [e.g., Xu et al., 2005]. Chao asserts, however, that while Chinese parenting may resemble some aspects of authoritarian or authoritative parenting as practiced by European Americans, it is distinct in its motivation and meaning. In deriving the parenting profiles for our sample of Chinese Americans, we were mindful of these previous studies, and we decided to use the term "tiger" parenting to label this distinct, and possibly uniquely Chinese, type of parenting. We felt that this label best captured the combination of warm and punitive parenting strategies that Chua [2011] described in her memoir.

\section{Deriving the Four Parenting Profiles of Chinese Americans}

We used latent profile analyses to arrive at four parenting profiles for our sample of Chinese American parents. Latent profile analyses were ideal for our purposes because they allowed flexibility in using multiple dimensions of parenting to arrive at various categories derived from the data. We conceptualized that relatively high and low levels of the four positive (warmth, inductive reasoning, monitoring, democratic) and four negative (hostility, punitive, psychological control, shaming) parenting dimensions in the sample would coalesce to form "tiger," "supportive," "harsh," and "easygoing" parenting profiles in our sample.

\begin{tabular}{|c|c|c|c|}
\hline & & \multicolumn{2}{|c|}{ Negative parenting } \\
\hline & & high & low \\
\hline Positive parenting & $\begin{array}{l}\text { high } \\
\text { low }\end{array}$ & $\begin{array}{l}\text { tiger } \\
\text { harsh }\end{array}$ & $\begin{array}{l}\text { supportive } \\
\text { easygoing }\end{array}$ \\
\hline
\end{tabular}

Of the eight parenting dimensions used in the study, shaming was the only culturally specific parenting dimension. This dimension is completely absent in the classic parenting styles. We included shaming because it has been found to be important in Chinese family socialization [Fung, 1999]. Levels of shaming were similarly high in tiger and harsh parents in our study. Supportive parents showed higher levels of shaming than easygoing parents, suggesting that a moderate level of shaming may be an important component of being a supportive and successful parent among Chinese Americans.

\section{Complexities around Tiger Parenting}

Chua's [2011] book emphasizes that tiger parenting is the mother's job. Our research finds that tiger fathers are also present in Chinese Americans families. Our finding is that tiger mothering is more likely to diminish as children grow older while tiger fathering is more likely to increase. We attribute this phenomenon to mothers and fathers changing their parenting styles to meet the developmental needs of the adolescent. In earlier adolescence, when children are more tied to the home, mothers 
are more likely to be the emotional caretakers of their children. In contrast, as children individuate and become more engaged with the outside world as autonomous adults, fathers may take on a more active role.

Although we examined eight parenting dimensions, our definition of tiger parenting is still limited. Scholars have noted that Chinese mothers emphasize effort and hard work rather than innate ability and rank school achievement as one of their primary parenting goals [Kim \& Wong, 2002; Li, 2012]; these findings could be taken into consideration in defining tiger parenting. In other words, a number of other aspects beyond the eight dimensions we identified, such as parenting goals and ideologies, can be added to produce a more nuanced definition of this culturally rooted parenting style.

\section{The Importance of Supportive Parenting in Chinese Americans}

My research on Chinese American families has consistently shown the beneficial effects of supportive parenting in thwarting negative developmental trajectories in Chinese American adolescents. For example, Kim and Ge [2000] demonstrate that parents' depressed mood sets in motion a family process of unsupportive parenting that relates to more depressive symptoms in Chinese American adolescents. With increases in monitoring and inductive reasoning and decreases in harsh parenting, Chinese American children experience fewer depressive symptoms.

We also demonstrated that supportive parenting may be a modifiable mediator between acculturation gaps between parents and children and the children's adjustment in Chinese American families [Kim, Chen, Li, Huang, \& Moon, 2009; Kim, Chen, Wang, Shen, \& Orozco-Lapray, 2013a]. An acculturation discrepancy in American orientation between parents and children is related to less supportive parenting practices (low levels of monitoring, inductive reasoning, and warmth) that create a sense of alienation between parents and children resulting in more depressive symptoms and lower academic performance (grade point average and standardized test scores) in Chinese American adolescents [Kim et al., 2013a]. These findings suggest that increasing supportive parenting practices, particularly for fathers, can disrupt this negative process, ultimately increasing optimal developmental outcomes among Chinese American children.

\section{Future Directions}

After the publication of my paper on tiger parenting, scholars from diverse disciplines ranging from law, to economics, to psychiatry, to statistics began contacting me. It appears that gaining a fuller understanding of tiger parenting would require a multidisciplinary approach and the combined expertise of a diverse group of scholars.

Scholarly research on parenting styles that have recently been popularized by the media has been sparse. For example, few, if any, developmental scholars have tackled the issue of "helicopter" parents. It is important that developmental scholars with a strong background in parenting research tackle these issues as a public service: We need to educate the public about the truths and myths behind the media's descriptions of different parenting styles and the ways in which different parenting strategies affect children's developmental outcomes. 
My research challenges the "model minority" stereotype of Asian American children and adolescents. For example, Asian Americans are often perceived as perpetual foreigners [Kim, Wang, Deng, Alvarez, \& Li, 2011], which undermines their mental health. Gaining a better understanding of the conditions that result in the achievement-adjustment paradox [Qin, 2008] of Asian Americans (in which positive psychological adjustment does not accompany a high degree of academic success) is an important avenue to pursue in future research focusing on Asian American children and their families.

\section{References}

Baumrind, D. (1966). Effects of authoritative parental control on child behavior. Child development, 37, 887-907.

Becker, W.C. (1964). Consequences of different kinds of parental discipline. In M.L. Hoffman \& L.W.H. Hoffman (Eds.), Review of child development research. Vol. 1 (pp. 169-208). New York: Russell Sage Foundation.

Chao, R.K. (1994). Beyond parental control and authoritarian parenting style: Understanding Chinese parenting through the cultural notion of training. Child Development, 65, 1111-1119.

Chao, R.K. (1995). Chinese and European American cultural models of the self reflected in mothers' child rearing beliefs. Ethos, 23, 328-354.

Cheah, C.S.L., Leung, C.Y.Y., \& Zhou, N. (2013). Understanding “tiger parenting” through the perceptions of Chinese immigrant mothers: Can Chinese and U.S. parenting coexist? Asian American Journal of Psychology, 4, 30-40.

Chua, A. (2011). Battle hymn of the tiger mother. New York: Penguin Press.

Darling, N., \& Steinberg, L. (1993). Parenting style as context: An integrative model. Psychological Bulletin, $113,487-496$.

Fung, H. (1999). Becoming a moral child: The socialization of shame among young Chinese children. Ethos, 27, 180-209.

-Juang, L.P., Qin, D.B., \& Park, I.J. (2013). Deconstructing the myth of the "tiger mother": An introduction to the special issue on tiger parenting, Asian-heritage families, and child/adolescent well-being. Asian American Journal of Psychology, 4, 1.

Kim, S.Y., Chen, Q., Li, J., Huang, X., \& Moon, U.J. (2009). Parent-child acculturation, parenting, and adolescent depressive symptoms in Chinese immigrant families. Journal of Family Psychology, 23, 426-437.

Kim, S.Y., Chen, Q., Wang, Y., Shen, Y., \& Orozco-Lapray, D. (2013a). Longitudinal linkages among parent-child acculturation discrepancy, parenting, parent-child sense of alienation, and adolescent adjustment in Chinese immigrant families. Developmental Psychology, 49, 900-912.

Kim, S.Y., \& Ge, X. (2000). Parenting practices and adolescent depressive symptoms in Chinese American families. Journal of Family Psychology, 14, 420-435.

Kim, S.Y., Wang, Y., Deng, S., Alvarez, R., \& Li, J. (2011). Accent, perpetual foreigner stereotype, and perceived discrimination as indirect links between English proficiency and depressive symptoms in Chinese American adolescents. Developmental Psychology, 47, 289-301.

Kim, S.Y., Wang, Y., Orozco-Lapray, D., Shen, Y., \& Murtuza, M. (2013b). Does “tiger parenting” exist? Parenting profiles of Chinese Americans and adolescent developmental outcomes. Asian American Journal of Psychology, 4, 7-18.

Kim, S.Y., \& Wong, V.Y. (2002). Assessing Asian and Asian American parenting: A review of the literature. In K. Kurasaki, S. Okazaki, \& S. Sue (Eds.), Asian American mental health: Assessment theories and methods (pp. 185-201). New York: Kluwer.

Li, J. (2012). Cultural foundations of learning: East and West. New York: Cambridge University Press.

Maccoby, E.E., \& Martin, J.A. (1983). Socialization in the context of the family: Parent-child interaction. In P.H. Mussen (Series Ed.) \& E.M. Hetherington (Vol. Ed.), Handbook of child psychology. Vol. 1: Socialization, personality, and social development (5th ed., pp. 1-101). New York: Wiley.

Qin, D.B. (2008). Doing well vs. feeling well: Understanding family dynamics and the psychological adjustment of Chinese immigrant adolescents. Journal of Youth and Adolescence, 37, 22-35.

Way, N., Okazaki, S., Zhao, J., Kim, J.J., Chen, X., Yoshikawa, H., Jia, Y., \& Deng, H. (2013). Social and emotional parenting: Mothering in a changing Chinese society. Asian American Journal of Psychology, 4, 61-70.

Xu, Y., Farver, J.M., Zhang, Z., Zeng, Z., Yu, L., \& Cai, B. (2005). Mainland Chinese parenting styles and parent-child interaction. International Journal of Behavioral Development, 29, 524-531. 